\title{
Introduction to heritage and climate change: current gaps and scientific challenges
}

\section{Claudio Margottini}

As conservation has been defined as the management of change (Fairclough 2003), undoubtedly it is also a way to face, or to adapt, to climate change. Climate change is one of the most significant global challenges facing the society, and that heritage properties are affected by the impacts of climate change is widely acknowledged (UNESCO World Heritage Centre, 2021a, 2021b). This section of the book explores some of the ways that research and practice on heritage and climate change have evolved over the past two decades.

Climate change is a significant and truly global problem, clearly associated with increased risks for humans, other species, landscapes and built infrastructures. When we consider heritage as the evidence of millennia of adaptations by humans to their environment, climate change is a very relevant and interesting topic. In the future, the results of climate change might be considered heritage. For the moment, however, the focus of this type of research is more on the heritage sites currently deemed important, looking at how they are continuously impacted by the results of climate change; both by major sudden natural hazards like heavy rainfall and floods but also by slow, cumulative processes such as erosion. As such events can also lead to large migration streams, and to long-term changes in landscape and land use, there are also heritage-related challenges that are more indirect, but not less significant.

This section focuses on the direct effects of issues that are either caused or compounded by the effects of climate change.

Climate follows the 'average weather', whereas disasters (depending on type) are strictly derived from local extreme weather conditions, occurring in a very short time window. Likewise, climate is a global process, whereas disasters very 
often involve quite local/district impact. In addition, there are limitations in the available data and in climate modelling, describing the future occurrence and impact of natural hazards. The field is occupied by different schools of thought and osmosis through disaster science and climate science is still very weak.

The Intergovernmental Panel on Climate Change (IPCC 2012) focused for the first time on interactions between extreme weather and climate events, and exposed and vulnerable human and natural systems. Some limitations still exist: confidence in projecting changes in the direction and magnitude of climate extremes depends on many factors, including the type of extreme event, the region and season, the amount and quality of observational data, the level of understanding of the underlying processes, and the reliability of the simulations in models.

Cultural heritage is exposed to a number of risks. These can be divided into geo-hazards (e.g. earthquakes and volcanic eruptions), hazards related to climate change (e.g. increased precipitation, flooding, droughts, heatwaves and rising sea levels) and other human-induced threats which are essentially social and economic in nature. The last group ranges from increased urbanization, mass tourism and traffic congestion to industrial air pollution and increasing energy demand (Jigyasu 2006).

While close attention is paid to the protection of human life and livelihoods, as well as economic infrastructure, the protection of cultural heritage has been somewhat overlooked and underprioritized. A key factor indicating the need to increase the resilience of heritage sites to the impacts of climate change is the particular fragility of their historic material, and thus their vulnerability to the effects of climate change and impacts of natural hazards (Chmutina et al. 2016). An attempt to classify the many impacts of climate change on cultural heritage is reported by Colette (2007).

The above discussion clearly shows how complex it is to couple cultural heritage (conservation) with climate change (Sabbioni et al. 2010). This is because the conservation of heritage is an evolving multidisciplinary field; especially in dealing with climate change. At the same time, climate change necessitates deeper knowledge of the mechanisms of atmospheric circulation and how to relate them to local extreme weather. Furthermore, as shown by ICOMOS (2019), the quantitative methods often used in climate literature might not easily match the narrative-based and qualitative methods generally applied when studying cultural heritage. This is one reason why cultural aspects have not been well integrated into climate change analyses and policies (Adger et 
al. 2013). The ICOMOS (2019) report presents examples of the mutual relationship between climate and heritage, where heritage not only contributes to climate change actions (e.g. climate adaptation and mitigation) but can be adversely affected by climate change impacts.

Having in mind the above-described complexity, and despite a high level of scholarly interest in climate change impacts on various natural and socioeconomic systems, only in the past decade has a comprehensive understanding begun to emerge of climate change impacts on cultural heritage at a global scale and across disciplines (Fatorić and Seekamp 2017). Fatorić and Seekamp (2017) carried out a systematic literature review. Applying their methodology and using the SCOPUS $\odot$ database, we found almost 300,000 publications on 'Climate Change', and almost 32,000 publications mentioning 'Cultural Heritage'. However, less than 500 publications have combined the two (1985-2020). While this number is low, there has been an increase in the last $10-15$ years (Figure 9.1).

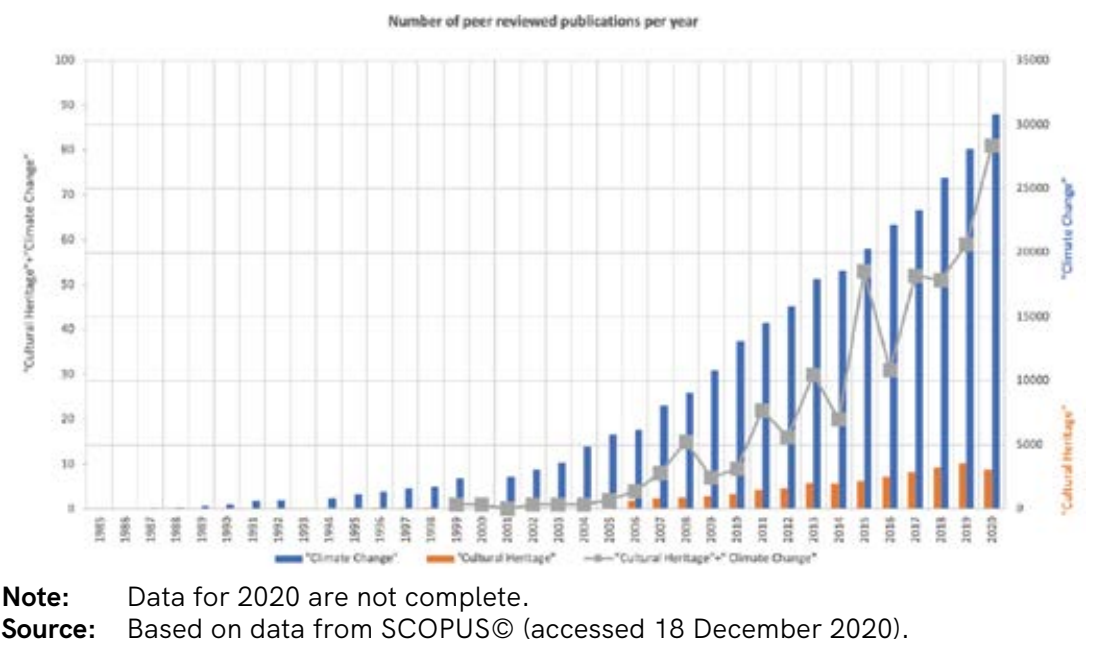

Figure 9.1 Number of peer reviewed publications stored in SCOPUS ( and retrieved for the terms 'Cultural Heritage' and 'Climate Change' (left axis) and 'Cultural Heritage' + 'Climate Change' (right axis) in the fields 'Article title', 'Abstract' and 'Keywords'

What is the reason for such a low level of scholarly interest, while the topic 'cultural heritage and climate change' is on the agenda of the most representative 
institutions dealing with conservation of heritage? From the data it is possible to discern, at least, a partial answer.

Apart from the more qualitative approach of cultural studies discussed previously (Adger et al. 2013), conservation of heritage is a typical interdisciplinary field, requiring expertise from material science, engineering science, architecture, earth science, social science, humanities and more. If we add climate change, the required sciences are even more numerous, from widely dispersed disciplines, adding complexity to the working group.

Another limitation is the geographical distribution of knowledge. Mapping the available data from SCOPUS $\odot$, it is possible to notice that the majority of scientific production is in Europe, followed by the US and Australia.

The final point is the support from funding agencies and institutions, at both national and international levels. Clear data are not available and only a few documents report detailed information. From the SCOPUS $\odot$ repository, it is possible to identify the sponsor of some of the collected documents. As a preliminary indication, the main funding agency for peer reviewed articles containing the terms 'Cultural Heritage Climate Change' in the period 1985-2018 was the European Commission.

The above discussion has tried to identify the importance of bringing climate change processes into the cultural heritage conservation. Climate change will have physical, social and cultural impacts on cultural heritage. It will change the way people relate to their environment. This relationship is characterized by the way people live, work, worship and socialize in buildings, sites and landscapes with heritage value. The resulting socioeconomic changes will have a greater possible impact on the conservation of cultural heritage than climate change alone (UNESCO 2006).

From the attention that the scientific community is paying to the evaluation of proper preventive and corrective actions for the safeguard of cultural heritage from climate change (and the related impact in terms of direct risks as well as indirect physical, social and cultural influence), it is clear that urgency and relevance are missing. Although both climate change and cultural heritage are attracting funding and researchers, the coupling of them is yet to reach maturity, even while the damage to individual monuments and sites is becoming more and more apparent.

There is certainly a need to shift the way of thinking about conservation of heritage, including long-term strategies for reducing the effects of climate change. 
For more sustainable heritage planning, it is advisable to study and apply human history, in terms of local expertise and traditional knowledge. During the last few millennia, human beings have faced similar periods when they were affected by natural variations in climate, and they adapted themselves to the changing environment through nature-based solutions. When possible, these ways, methods and structures should be applied again. Proper land-use planning and management, as well as modern structural and non-structural intervention, are the other ways of operating (Cohen-Shacham et al. 2016).

Finally, the European Commission is recognized in many sectorial publications as the most relevant programming and funding institution for mitigating the effects of climate change on cultural heritage. Unfortunately, its efforts are still not enough to preserve the legacy of our past. Considering the traditional and well-known long perspective of European Union policy on science, we are expecting new and innovative programmes, for the benefit of European and worldwide citizens (Kropp et al. 2011).

The present section focuses on some of the problems introduced above, showing how interdisciplinary approaches can provide new insights into archaeology and conservation sciences. One example is PROTHEGO, where innovative monitoring of climate-related threats to cultural heritage, such as landslides and subsidence, can be implemented through satellite radar interferometry, with low environmental impact and high accuracy.

The project CLIMA focused on the important topic of impacts of soil erosion on buried or rupestrian archaeological sites, also magnified by climate change. New modelling and Gamma Spectrometer processing chains from remote sensing provided high-resolution input data, suitable to assess hazard and vulnerability maps for risk analysis.

Finally, EUWATHER focused on cross-cutting fluvial systems such as rivers and canals in Europe, where people initially settled down and these areas then grew and developed. This is a very interesting example of the deep interconnections between environmental change and archaeology.

\section{References}

Adger N.W., J. Barnett, K. Brown, N. Marshall and K. O’Brien (2013), 'Cultural dimensions of climate change impacts and adaptation', Nature Climate Change, 3, 112-17. 
Chmutina, K., R. Jigyasu and L.S. Bosher (2016), 'Understanding the impacts of climate change on cultural heritage buildings: a case of York, UK', Presented at the CIB World Building Congress: Intelligent Built Environment for Life, Tampere, Finland, 30 May-3 June, 188-98.

Cohen-Shacham, E., G. Walters, C. Janzen and S. Maginnis (eds) (2016), Nature-Based Solutions to Address Global Societal Challenges, Gland, Switzerland: IUCN, xiii, 97.

Colette, A. (ed.) (2007). Climate Change and World Heritage, UNESCO World Heritage Reports 22.

Fairclough, G. (2003), 'Cultural landscape, sustainability and living with change?' in J.M. Teutonico and F. Matero (eds), Managing Change: Sustainable Approaches to the Conservation of the Built Environment, 4th annual US/ICOMOS International Symposium, Philadelphia, Pennsylvania, the Getty Conservation Institute, April 2001, Getty Conservation Institute, Proceedings series, J. Paul Getty Trust, 23-46.

Fatorić, S. and E. Seekamp (2017), 'Are cultural heritage and resources threatened by climate change? A systematic literature review', Climatic Change, 142, 227-54.

ICOMOS (2019), The Future of Our Pasts: Engaging Cultural Heritage in Climate Action, 1 July 2019, Paris: ICOMOS.

IPCC (2012), 'Managing the Risks of Extreme Events and Disasters to Advance Climate Change Adaptation. A Special Report of Working Groups I and II of the Intergovernmental Panel on Climate Change', in C.B. Field, V. Barros, T.F. Stocker, D. Qin, D.J. Dokken, K.L. Ebi, M.D. Mastrandrea, K.J. Mach, G.-K. Plattner, S.K. Allen, M. Tignor and P.M. Midgley (eds), Cambridge and New York: Cambridge University Press.

Jigyasu, R. (2006), 'Integrated framework for cultural heritage risk management', Disasters and Development, 1 (1), accessed 11 May 2021 at: https://nidm.gov.in/ journal.asp.

Kropp, J.P., G. Walker, S. Menoni et al. (2011), 'Risk future in Europe', in S. Menoni and C. Margottini (eds), Inside Risk: A Strategy for Sustainable Risk Mitigation, Padua, Italy: Springer Verlag, 187-244.

Sabbioni, C., P. Brimblecombe and M. Cassar (2010), The Atlas of Climate Change Impact on European Cultural Heritage: Scientific Analysis and Management Strategies, London and New York: Anthem Press.

UNESCO (2006), Issues Related to the State of Conservation of World Heritage Properties: The Impacts of Climate Change on World Heritage Properties. WHC-06/30.COM/7 .1, Distribution limited.

UNESCO World Heritage Centre (2021a), UNESCO World Heritage Centre Compendium [online]. UNESCO World Heritage Centre. Accessed 11 May 2021 at: https://whc.unesco.org/en/compendium/80.

UNESCO World Heritage Centre (2021b), Climate Change and World Heritage [online]. UNESCO World Heritage Centre. Accessed 11 May 2021 at: https://whc .unesco.org/en/climatechange/. 